26th. Going on farourably, and from this date till the 4 th of May, had the æther three times daily, and once daily till the 17th. Pills given every fourth hour. On the 26th æther discontinued. On the 8th of May began to walk, and on the 9 th got down stairs. He is now able for work.

Owing to carelessness on the part of the patient's friends, he did not get so many pills as ordered; he had, however, about thirty, and his teeth were not affected.

The foregoing case differs from all other cases that I have met with, in having 80 many days threatened before it made its real attack The severity of the spasms, by being less marked on the chest than on the other parts of the body, afforded a better opportunity for the administration of the æther, at the same time that the great congestion of the lungs and head consequent on violent spasms of the chest was in great measure prevented. The marked influence of the xther on the spasms in their worst state, and the stiil more marked influence on the great rigidity of the muscles in the chronic state, prove it to be an agent of great power in spasmodic action of the muscles. Even three weeks after the invasion of the disease, the legs and thighs were so rigid as to require the exertion of all my power, added to the patient's own exertion, to flex them on the abdomen, but after having had the ather he flexed and extended them himself with facility.

In using the æther at first I was careful not to give it him in its strongest state, owing to its great effect on the already excited muscles of the throat, but afterwards he had it as strong as we could give it him, using hot water to increase the evaporation, and exhausting from one and a half to two ounces of the strongest æther at each administration. The spasms were always allayed by it, increasing during the interval, making him long for our re-visiting him; his only cry was that we did not give him enough of it.

This case, and one reported formerly from the North Dispensary, seem to me to be as convincing proofs of the efficacy of æther as any that have appeared.

The case I allude to was the reduction of a dislocation of the femur into the ischiatic notch, of five weeks' duration, less two days, and the patient, a powerful navigator, forty years of age. Two sets of pullies were applied to him with different fastenings to the thigh; the strain was kept up by one set, but the other set was also kept up so nearly to the same strain, that on the slightest slip of the principal pullies, the second set took their place. The strain was kept for one hour and a half, and during the whole of the time he was under the influence of the æther. It was about six weeks afterwards before he could walk ifreely.

June 10, Everton, Liverpool.

\section{THREE CASES OF}

NON-MALIGNANT TUMOUR OF THE UTERUS, ACCOMPANIED BY THE USUAL SYMPTOMS OF CANCER OF THE UTERUS.

By E. J. Shearman, M.D., Rotherham, Member of the Royal College of Physicians.

(Read before the Sheffield Medical Society, March 4, 1817.)

In the Dublin Medical Journal for 1842, Dr. Mantgomery says, "the disease of cancer uteri is too universally recognized as one of the most frightful scourges of humanity, to render it necessary for me to attempt any description of its horrors, or to impress on even the most junior of my hearers the importance of closely studying the phenomena of an affection, hitherto found so utterly intractable by every known means; and which, when once fully established, entails upon the unhappy sufferer, one unbroken train of miseries, from which it has been truly said, 'temporary relief can be found only in opium, and permanent rest only in the grave.' But I am perfectly convinced, from many years' observation, that something may be done, to stem, at its source, the torrent of agonies that will otherwise orerwhelm the patient; nay, I firmly believe it may, in many instances, be altogether turned aside, and the victim be rescued from the sad fate impending over her."

Agreeing perfectly in this opinion, and having during the last twenty years of my practice met with many anomalous cases simulating cancer uteri, which, (until the late improvements in the diagnosis of such cases,) were allowed to run their uninterrupted course, I am induced to lay before the members of this Society the following cases, which have occurred in the last two years, and which $I$ hope are not altogether uninteresting, as they have long been submitted to the tests of sight, touch, and manual manipulation,methods, which until very lately, have not been fully made use of by medical practitioners for ascertaining such diseases.

\section{Case I.}

A single lady, aged 48, consulted me in June, 1845 , in order to obtain relief from the pains produced by what her medical attendant called "cancer of the womb." She gave me the following history of her disease :-Two years ago she was, and had been all her life, perfectly regular; she was menstruating at the time she teceived a very sudden and heart-rending shock by the sudden death of a valued friend; the catamenial discharge suddenly stopped, and never re-appeared in a bealthy form. From that time to the present she has suffered from occasional sharp pains in the back and loins, traversing along the crest of the ilia and groins, often shooting down the front of the thighs; and this pain was attended with frequent discharges of sanious Guid, mixed with clotted blood, in various quantities. Fatsurly these pains have taken on a periodical type and incrtaned in violence, commencing about seren 
o'clock at night and continuing till five or six o'clock still retains it. The drawing, No. I., obligingly made the following morning, when she became perfectly easy. by my friend Dr. Branson, shews very accurately a Her nights were wretched; her appetite bad; muscles microscopic view of a portion of it magnified 250 emaciated; and that peculiar discolouration of skin, diameters, which proves it to belong to the class of and painful and anxious expression of the face so fibrous tumours.

commonly found in scirrhus uteri was very remarkable in this lady. She had no leucorrhœal discharge, but the bladder and rectum were irritated and difficult to manage. I could only succeed in introducing (and that with the greatest difficulty - the hymen being unruptured) Salmon's speculum ani into the vagina, but I managed, with the aid of a good lamp, to clearly ascertain the absence of the least increase of size, form, or density of the cervix uteri, and the os uteri was quite normal. I assured her she was not suffering from cancer, prescribed acetate of morphia, iodine, and iron, which soon relieved her acute sufferings, and she returned home to her friends at some distance.

In July, 1846, I was sent for to see her at her residence, and there met her two medical attendants, who had succeeded in convincing her she was labouring under cancer of the vomb, and that she had not long to live. She was greatly emaciated, constantly bleeding from the uterus, her nocturnal pains had become intolerable, and she told me her life was a burden to her. I succeeded in dilating the vagina with a sponge tent, introduced with great difficulty Simpson's Speculum Vaginæ, and through that his uterine sound, fire inches and a half into the uterus, which I examined from the abdomen in front and through the rectum behind, and found perfectly moreable. A deluge of blood followed this examination, but I was quite satisfied the reck and mauth of the uterus were not diseased. I assured her she had no cancer; but that her disease consisted of a tumour of some kind in the uterus. I gradually dilated the vagina and os uteri by means of sponge tents and Simpson's uterine dilators, until I could see and feel the tumour in the uterus. I then introduced the uterine sound, passed it all round the uterus to ascertain the nature of the tumour, and during that operation $I$ accidentally detached the tumour from the lining membrane, and it came away with considerable hæmorrhage, in one piece, weighing four ounces. The hæmarrhage ceased under the influence of ergot; the nocturnal periodical pains became very much diminished, and $I$ was in great hope my patient would get well; but in the course of a few weeks the old periodical pains and discharge returned; and on a fresh examination with the speculum and uterine sound, I discorered a new growth of tumour.

I am sorry I cannot shew this tumour, I sent it up to Pnofessor Simpson, of Rdinburgb, for the purpose: of ebtrining bis opinion respecting the case, and be

There being no pedicle to this tumour, I could not expect to detach it again advantageously; I therefore determined to try the effect of iodine internally and externally, in the form of tincture, balls, and injections, assisted by quinine and iron, and acetate of morphia, to relieve the pain. I have pursned this plan for four months; the result is she has less uneasiness of every description; her nights are good; her appetite, strength, and flesh have improved; and the tumour, as ascertained by the uterine sound, has decreased in size an inch and a half; the os and cervix uteri remain perfectly normal. She is now quite convinced that her disease is not cancer, and lives in hope that she may. erentually be quite cured.

\section{CASE II.}

A delicate hysterical female, aged 35, married five years without ever having been pregnant, was attacked soon after marriage with severe burning, agonizing, and lancinating pains, referred to the neck of the womb, and extending from pubis to sacrum, thence down the thighs. These pains came on periodically every night about ten o'clock, and increased in intensity until about six in the morning. She was quite free from pain during the day. The pain on coition was excruciating. She had very frequent hæmorrhage, and when this ceased, a sanious kind of matter, mixed with a fluid resembling pus in appearance, kept her constantly wet and uncomfortable; added to which the bladder and rectum were very irritable.

When she consulted me, in July, 1846, for what she: 
had been led to believe was cancer, she was emaciated, had a greenish sallow complexion, with that pceuliar appearance in the countenance indicating inalignant disease. I examined the uterus by means of the speculum, found the os healthy, but the cervix elongated and rather narrow; the least touch with either my finger or the sound gave her great agony; I therefore desisted, and gave a cautious opinion. Iron, quinine, and morphia, with astringent and sedative injections, refieved the symptoms so much, that in October Inst I was enabled to introduce the uterine sound, which penetrated the uterus to three inches and a half, and I easily discovered by examination from the rectum and abdomen that the uterus was not attached to any other organ, but was, at its fundus, much larger than natural. 'I dilated the os uteri with Simpson's dilator, and then foind a tumour apparently attached all rouna. I got hold of a bit of this with a pair of long forceps, cut it off, macerated it in spirit of turpentine, and examined a thin slice of it under the microscope, a specimen of which Dr. Branson has also kindly delineated for examination. (Drawing No. II.)

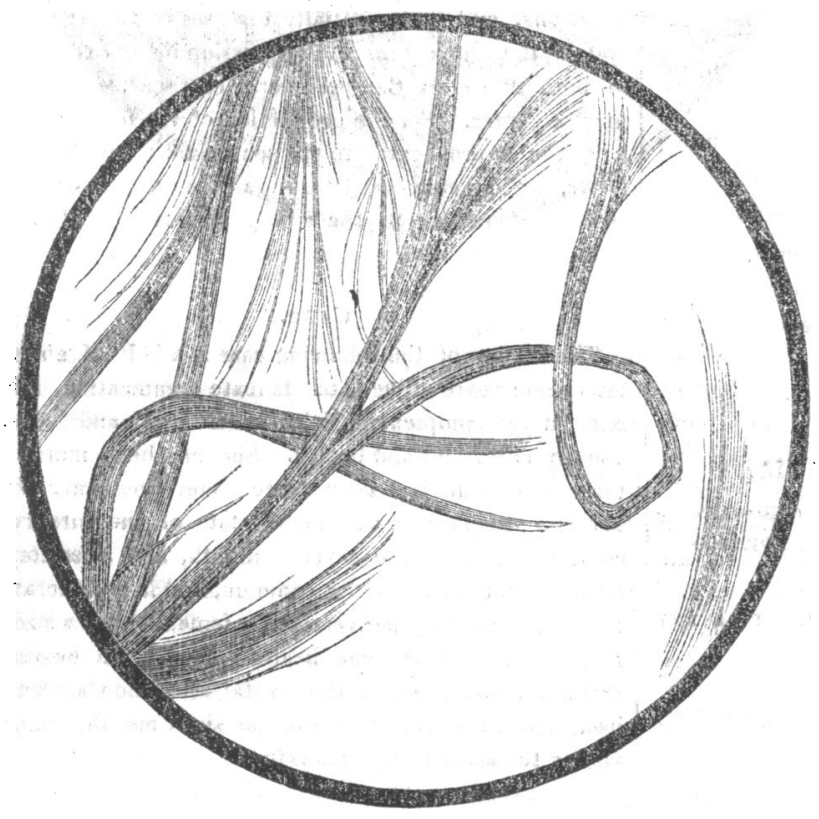

"A lady, aged 63, laboured nnder some obscure symptoms for more than two years, which induced her medical attendant to believe that she had some disease of the bladder. One day she was seized with sudden and profuse discharge of blood from the vagina, accompanied with sharp uterine pains, like those of incipient labour or miscarriage. I was then called to her, and informed by her surgeon that she had some disease of the womb, which lie believed to be scirrhus. On examination I discovered that the os uteri was a little dilated, and very thin, with something protruding from the uterus, the nature of which could not at that time be correctly ascertained. She had long been suffering periodical pains in the region of the pelvis. I directed some ergot of rye, and on the following morning I found that the tumour had descended much lower. I passed Simpson's sound into the uterus, and carried it quite around it twice. Two hours after a large fibrous tumour came away, without pain, and the hæmorrhage ceased; it was larger than a commonsized kidney, with an attachment about the size of a shilling, and it appeared to come away clearly and entirely. All the former symptoms disappeared, and she rapidly iniproved. This amendment, however, did not last long; for about a month afterwards, periodical pains re-appeared about the region of the uterus, and some discharge. A most careful examination failed to detect any cause for these symptoms, which, although occasionally relieved, never subsided for any length of time. It is now more than three months since the tumour was removed; the pains are more severe, and generally occur every afternoon or evening, and resemble those of cancer in its early stage; the discharge, too, is more profuse and bloody, so that its effects are visible in the countenance and constitution. Her sleep and appetite are becoming impaired. I have repeatedly examined ber with great care, but can detect nothing more than an enlarged, painful, and indurated state of the uterus, but $I$ do not find any ulceration, or even thickening,

Finding this also was a fibrous substance of the same description as the first case, I resolved to let it alone, and try the effect of iodine internally and externally, by means of introducing the tincture into the uterus, injections, and balls. The result is, that by these means, aided by tonics and the cold shower-bath, the tumour has almost if not quite disappeared, and with it the whole of the distressing symptoms which were so similar to cancer as to have induced more than one practitioner of eminence to call the disease by that name.

\section{Case III.}

This case has been selated to me by my friend Dr. Toogood, of Torquay, which I will gire in his own words. of the neck. Thinking there might be another growth, I dilated the 08 uteri with sponge tent, and examined that organ internally, without discovering any cause for the symptoms. She is generally free from pain urtil towards evening, when dreadful pain comes' on. At first this did not happen every evening, but now she scarcely passes a day without much pain."

The only tumours growing from the internal membrane of the uterus described by authors, are soft and hard polypi, encephaloid, caulifiower excrescence, hæmatoma, scirrbus, and fibrous; the latter often running into osseous and calcareous tumonrs. The symproms and progress of these diseases are quite diffetent from those I have described; and I harb 
consulted the works of Dr. Montgomery, Dr. Davis, Dr. Lee, Dr. Churchill, Dr. Lever, Ingleby, Dr. Gooch, Dr. Ashwell, Dr. Marshall Hall, Dr. Henry Bennett, Boivin and Dugés, by Hemming, and Mr. Lee's Prize Essay, and can find no notice of a disease like the three cases detailed, all of which might be so easily mistaken for scirrhus and cancer, unless examined carefully by the aid of Simpson's speculum sound and dilator.

The first morbid change which takes place in scirrhus nteri is induration in and around the muciparous glands or resicles, called by some ova Nabothi, which exist in great numbers in the cervix and margin of the os uteri. This induration is caused by the deposition of scirrhous or tuberculous matter, which thickens the parts, and gives them a greater volume, so that ther feel unequal, bumpy, and knotty, like the ends of one's fingers drawn together; but in the cases described, no thickening or hardness can be either seen or felt. The severe pains are difficult to account for, unless the irritation and stretching of the neck of the uterus by the tumour can be considered sufficient; but even then, it is still more difficult to account for the absence of pain in the day time.

The periodical nature of the acute pain attending such fibrous turours, which so nearly resembles that suffered in cases of cancer uteri, and the relief afforded by the treatment with iodine, will, I trust, be considered by the members of this Society, a sufficient apology for introducing the subject to their notice.

Rotherham, March 4, 1847.

\section{CASE OF PUERPERAL MANIA,}

OCCURRING AT AN EARLY PERIOD OF UTERO-GESTATION, AND RELIEVED BY INDUCED ABORTION.

TO THE EDITOR OF THE PROVINCIAL MEDICAL AND Sir, SURGICAL JOURNAL.

I propose from time to time to send you a few cases and observations copied from my note book, for publication in the Journal. Sbould you consider the present communication of sufficient value, you will oblige me by inserting it,

I am Sir, your obedient servant, THOMAS SALTER, F.R.C.S.

Poole, May 20, 1847.

Puerperal Mania as its name injplies, is unsoundness of mind occurring in the puerperal state, and most frequently from three to ten days after delivery, owing its origin to a peculiar irritation of the uterus derived from its previons impregnated condition. The peculiarity of the case about to be related, and to which it chiefly owes its interest, is the occurrence of mental diseate antecedently to parturition, and at 80 early a period of gestation.

The various sympathetic derangements of the fanctions of the body resulting from uterine impregnation, in ordinary cases, sufficiently attest the intimate connection subsisting between the womb and its append. ages with the organs of organic life, and the frequent functional disturbance of the sensorium and the spinal system of nerves, as clearly manifest its influence on animal life. I am not aware that there is any case recorded similar to the one $I$ am about to relate, but $I$. know of no reason why such should not have happened; indeed Dr. Ramsbotham observes, that puerperal maniq sometines occurs during pregnancy; and it may be inferred from the introductory remarks of Dr. Gooch, to bis chapter "On disorders of the mind in lying-in women," that he also was aware of the fact.

Puerperal convulsions mostly occur during labour, or, as in the case of puerperal mania, soon after delivery, but convulsions precisely similar are also sometimes observed, (though rarely,) at different periods of utero-gestation. Some years since 1 had a patient who was thus affected in several of her pregnancies, commencing at an early period after impregnation, and who, in every instance, went on to her full timo, and without any apparent injury to herself or child. Puerperal mania and puerperal convulsions are kindred affections, and are essentially diseases of the nerrous system, the primary morbid impression being exercised in both cases on the peripheral extremities of the uterine nerves. For the production of the former, the irritation is propagated to the sensorium; and for the latter, being conveyed through the excito-motory system of nerves to the spinal marrow and brain, induces the epileptic paroxysms.

\section{Case.}

The subject of the following case is a lady of about thirty-one years of age, of delicate organization, fair and ruddy complexion, with dark hair and eyes, usually enjoying good health. She has been married. three years and has been three times pregnant. In her first pregnancy a disordered state of the intellect commenced about the seventh month, and after continuing a fortnight, labour came on, and in a moderate time she was safely delivered of a female child, who is now living and in good health. She again proved pregnant, and this time the mental alienation showed itself about the termination of the sixth month, manifesting the same symptoms as in the preceding attackconstant restlessness, almost total absence of sleep, and such a degree of violence of manner, as often to require four or five persons in constant attendance upon ber night and day. After continuing in this state for two or three weeks, it appeared to the medical gentleman under whose care she was, necessary to bring on labour, by rupturing the membranes and evacuating the liquor amnii. This was accordingly done and in five days she gave birth to a still-born child. The violent paroxysms of insanity which before threatened her life, two days after this event ceased, and she gradually recovered her former state of mind. Soon after her removal to this neighbourhood, from the north of England, her former place of residence, she became pregnant a third time, and on this occarion the unsoundness of mind showed itself shortly after she had passed the fourth month. From this period 